\title{
ADOLESCENT OBESITY AND ASSOCIATED CARDIOVASCULAR RISK FACTORS OF RURAL AND URBAN LIFE (ESKISEHIR, TURKEY)
}

\author{
Mehmet Enes Gökler, Necati Buğrul, Selma Metintaş, Cemalettin Kalyoncu \\ Public Health Department, Medical Faculty, Eskisehir Osmangazi University, Meselik-Eskisehir, Turkey
}

\section{SUMMARY}

Introduction: The purpose of this study is to determine the prevalence of obesity and to compare the associated risk factors between the adolescent children living in rural and urban areas.

Materials: This cross-sectional study conducted among 3,918 high school students getting education in the city centre and rural areas of Eskisehir. A specially designed questionnaire form included questions about socio-demographic characteristics as well as cardiovascular risk factors including smoking status, diet habits (breakfasting, consumption of sugar-sweetened beverages and fruit and vegetable consumption), physical activity and time spent on computer and/or television.

Results: The prevalence of being overweight was $10.4 \%$ and $12.2 \%$ and the prevalence of obesity was $7.9 \%$ and $11.3 \%$ in rural and urban areas, respectively. In urban areas, being overweight was accompanied by prehypertension ( $\mathrm{OR}=2.3,95 \% \mathrm{Cl} 1.6-3.3)$, hypertension $(\mathrm{OR}=2.3,95 \% \mathrm{Cl}$ 1.6-3.2), and family history of cardiovascular disease ( $\mathrm{OR}=1.3,95 \% \mathrm{Cl} 1.1-1.7)$, and obesity was accompanied by prehypertension ( $\mathrm{OR}=2.3,95 \%$ $\mathrm{Cl} 1.6-3.3)$, hypertension ( $\mathrm{OR}=3.9,95 \% \mathrm{Cl} 2.9-5.3)$, excessive use of computer/TV ( $\mathrm{OR}=1.3,95 \% \mathrm{Cl} 1.1-1.7)$, having no breakfast ( $\mathrm{OR}=1.3$, $95 \% \mathrm{Cl} 1.1-1.7)$, physician-diagnosed diabetes mellitus ( $\mathrm{OR}=4.2,95 \% \mathrm{Cl} 1.3-14.1)$ and consumption of sugar-sweetened beverages (OR $=0.6$, $95 \% \mathrm{Cl} 0.5-0.8)$. In rural areas, although the variables accompanying being overweight were parallel with those in urban areas, obesity was only associated with prehypertension ( $\mathrm{OR}=6.1,95 \% \mathrm{Cl} 2.6-14.1)$, hypertension $(\mathrm{OR}=22.1,95 \% \mathrm{Cl} 9.9-49.3)$ and family history of cardiovascular disease $(\mathrm{OR}=1.6,95 \% \mathrm{Cl} 1.1-2.6)$.

Conclusion: Risk factors may differ in the adolescents from rural and urban areas. It is important in overweight and obese children to assess the family history of cardiovascular disease, blood pressure and blood glucose, to ask about the habit of regularly breakfasting, and to evaluate time spent on computer/TV. As in urban areas, environmental regulations also become important in rural areas. Appropriate social activities for children to spent more time outdoor, e.g. in parks or playgrounds, are important in urban as well as in rural areas.

Key words: adolescent, obesity, cardiovascular risk factors, rural-urban study

Address for correspondence: M. E. Gökler, Eskisehir Osmangazi University, Medical Faculty, Public Health Department, Genclik Boulevard, 26480 Meselik-Eskisehir, Turkey. E-mail: enesgokler@gmail.com

\section{INTRODUCTION}

Obesity is a growing health problem all over the world and affects people of all ages (1). Overweight and obesity in children and adolescents lead to co-morbidities such as hypertension, type 2 diabetes, dyslipidemia, and metabolic syndrome in the future (2, 3). According to the global data, the prevalence of overweight and obesity in adolescence increased from $4.2 \%$ in 1990 to $6.7 \%$ in 2010 , and has been estimated to increase to $9.1 \%$ in 2020 . There are approximately 43 million overweight or obese children and additional 92 million are at risk of being overweight in the world, particularly in the developing countries (4).

Development of the adolescent obesity is affected by many factors and mainly results from the imbalance between caloric intake and energy expenditure (5). As a result, the prevalence of overweight and obesity varies between developed and developing countries as well as between rural and urban areas of a country $(6,7)$. These differences result from the genetic predisposition of the communities as well as from sedentary behaviour, changes in diet habits and lack of physical activity (8).
Because of the rural-urban migration, urban life in Turkey does not always result in a positive health approach and have different effects than expected on health problems such as obesity and hypertension associated with healthy behaviours. Although the differences in the prevalence of obesity and hypertension between rural and urban areas for adult population have been previously reported, there are limited data for adolescent population, even though the adolescence is the life period during which the individual is most affected by social changes and prone to risky behaviour and habits (9).

The purpose of this study is to determine the prevalence of obesity and to compare the associated risk factors between the adolescent children living in rural and urban areas.

\section{MATERIALS AND METHODS}

This cross-sectional study was conducted among high school students getting education in the city centre and rural areas of Eskisehir between March 2012 and February 2013. 


\section{Subjects}

The study was conducted on a sample of high school students from rural and urban settlements in Eskisehir Province located in the Central Anatolia Region. Eskisehir is among the more developed provinces of Turkey but its rural areas are still under development. Based on the register as of 2012, the population of Eskisehir totals 789,750 people. There are 35,004 students in urban areas and 4,563 students in rural areas at the Eskisehir's high schools.

This research has been planned as a school screening study in high school. Turkish students completing primary education have to take an exam to enrol to Anatolian high schools or vocational high schools. The students accepted to the Anatolian high schools are more successful in the exam than those accepted to vocational schools.

\section{Ethical Considerations}

The required permissions for conducting the study were obtained from school administration and Eskisehir Osmangazi University Ethics Committee (approval number 11/06.12.2012) and informed verbal consent was obtained from each student.

\section{Study Design and Sample Size}

A two-stage stratified sampling method was used to determine the schools that will be included in the study. The sample size was 3,457 with a margin of error of $1 \%$, and considering the frequency of associated cardiovascular risk factors as $10 \%$. Two districts in the city centre and 12 districts in the periphery of Eskisehir were selected by random sampling. The schools in the districts were stratified by their education programmes. The schools were selected from each stratum (Anatolian high schools and vocational high schools) in proportion to the number of students in schools. Class 1-3 students from 16 high schools were visited and available $2,870(82 \%)$ students in the city centre and $1,048(72 \%)$ students in the periphery $(3,918$ students in total) were included in the study.

\section{Procedure}

The questionnaires used in the study were filled in by the students under supervision in about $30 \mathrm{~min}$. The specially designed questionnaire form included questions about socio-demographic characteristics as well as cardiovascular risk factors including smoking status, diet habits (breakfasting, consumption of sugarsweetened beverages and fruit and vegetable consumption), physical activity and time spent on computer and/or television. After the completion of the questionnaire, body height, weight and arterial blood pressure of each student were measured and recorded.

Obesity was assessed by using WHO criteria $(<85$ th percentile, normal; $85-95$ th percentile, overweight; and $\geq 95$ th percentile, obese) (10).

An automatic blood pressure monitor (OMRON M2) was used for measurement of blood pressure (11). According to the reference limits of the "Fourth Report for Diagnosis, Evaluation, and Treatment of High Blood Pressure in Children and Adolescents" published by the American Academy of Paediatrics, the blood pressure of $<90$ th percentile was considered as normal, 90-95 percentile as prehypertension and $\geq 95$ th percentile as hypertension (12).
WHO STEPS criteria used in the WHO study of health behaviour in school-aged children was used to evaluate the nutrition, physical activity and time spent on computer and/or television. Physical activity was measured by asking questions on four different aspects of it; physical activity at the school, physical activity during recreation time, physical activity on the way to school, and the time of physical rest. To define low level of activity $<600$ MET-minutes were considered. Inappropriate use of computer/TV was defined as spending 4 hours or more daily on computer and/or TV. Dietary habits were assessed as follows: inadequate fruit and vegetable consumption was defined as consuming $<5$ combined servings of fruit and vegetables per day. Inadequate consumption of sugar-sweetened beverages was defined as consuming one or more sugar-sweetened beverages per day. Having breakfast was defined as eating breakfast every school day (13).

\section{Statistical Analyses}

Data were analyzed by using chi-square test as a univariate analysis and multiple logistic regression as a multivariate analysis. Logistic regression analysis determined the socio-demographic characteristics affecting obesity (age, gender, family income level, dwelling of the student). As a second step, following the adjustment for socio-demographic variables affecting obesity and for variables at $\mathrm{p}<0.10$ significance level in univariate analysis, the model was constructed to determine the independent variables affecting obesity for rural and urban areas separately.

\section{RESULTS}

Of the 3,918 students included in the study, 52.2\% were females and $47.8 \%$ were males. The age of the students ranged from 14 to 18 years, with a mean age of $15.72 \pm 0.99$ years. Distribution of adolescents from rural vs. urban areas according to certain socio-demographic characteristics is given in Table 1.

Compared to the high school students from urban areas, those from rural areas were mostly males, aged 16 years or older, had a low income level and were boarding students. Distribution of adolescents from rural vs. urban areas according to obesity and other features is given in Table 2 .

Of the students comprising the study group, $11.7 \%$ were considered overweight and $10.4 \%$ obese. The prevalence of being overweight was $10.4 \%$ and $12.2 \%$ and the prevalence of obesity was $7.9 \%$ and $11.3 \%$ in rural areas and in urban areas, respectively. Similarly, the prevalence of prehypertension, hypertension and physical inactivity was higher in the urban vs. rural areas. On the other hand, prevalence of smoking, inadequate fruit-vegetable consumption and inappropriate use of computer/TV were higher in rural vs. urban areas. Adjusted OR and 95\% CI values for the risk factors accompanying obesity and being overweight in adolescents according to dwelling sites is given in Table 3 .

In urban areas, being overweight was accompanied by prehypertension, hypertension and family history of cardiovascular disease and obesity was accompanied by prehypertension, hypertension, excessive use of computer/TV, having no breakfast, physician-diagnosed diabetes mellitus, and consumption of sugar-sweetened beverages. In rural areas, although the variables accompanying being overweight were parallel with those in the 
Table 1. Distribution of adolescents from rural vs. urban areas according to certain socio-demographic characteristics

\begin{tabular}{|c|c|c|c|c|}
\hline & $\begin{array}{l}\text { Urban } \\
\mathrm{n}(\%)\end{array}$ & $\begin{array}{l}\text { Rural } \\
\mathrm{n}(\%)\end{array}$ & $\begin{array}{l}\text { Total } \\
\mathrm{n}(\%)\end{array}$ & $p$ \\
\hline \multicolumn{5}{|l|}{ Gender } \\
\hline Male & $1,338(46.6)$ & $536(51.1)$ & $1,874(47.8)$ & \multirow{2}{*}{0.012} \\
\hline Female & $1,532(53.4)$ & $512(48.9)$ & $2,044(52.2)$ & \\
\hline \multicolumn{5}{|l|}{ Age group } \\
\hline $14-15$ & $1,435(50.0)$ & $395(37.7)$ & $1,830(46.7)$ & \multirow{2}{*}{$<0.001$} \\
\hline 16 years and over & $1,435(50.0)$ & $653(62.3)$ & $2,088(53.3)$ & \\
\hline \multicolumn{5}{|c|}{ Family income (monthly) } \\
\hline$<\$ 300$ & $144(5.1)$ & $204(19.7)$ & $348(8.9)$ & \multirow{3}{*}{$<0.001$} \\
\hline$\$ 301-600$ & $842(29.3)$ & $555(53.7)$ & $1,397(35.8)$ & \\
\hline$>\$ 601$ & $1,884(65.6)$ & $275(26.6)$ & $2,159(55.3)$ & \\
\hline \multicolumn{5}{|l|}{ Residence } \\
\hline With a host family & $2,361(82.3)$ & $625(59.9)$ & $2,986(76.3)$ & \multirow{3}{*}{$<0.001$} \\
\hline Dormitory-boarding & $463(16.1)$ & $343(32.9)$ & $806(20.6)$ & \\
\hline Other & $46(1.6)$ & $76(7.2)$ & $122(3.1)$ & \\
\hline
\end{tabular}

Table 2. Prevalence of obesity and certain cardiovascular risk factors in adolescents and adjusted OR and $95 \% \mathrm{Cl}$ values for cardiovascular disease risks in rural areas compared to urban areas

\begin{tabular}{|c|c|c|c|c|c|c|}
\hline & \multicolumn{2}{|c|}{ Urban } & \multicolumn{2}{|c|}{ Rural } & \multirow{2}{*}{$\begin{array}{c}\text { Total } \\
\text { Prevalence \% } \\
(95 \% \text { Cl })\end{array}$} & \multirow[b]{2}{*}{$p$} \\
\hline & $\begin{array}{l}\text { Prevalence \% } \\
\quad(95 \% \mathrm{Cl})\end{array}$ & $O R^{*}$ & $\begin{array}{l}\text { Prevalence \% } \\
\quad(95 \% \mathrm{Cl})\end{array}$ & $\mathrm{OR}^{*}(95 \% \mathrm{Cl})$ & & \\
\hline Overweight & $12.2(11.0-13.4)$ & 1 & $10.4(8.6-12.2)$ & $0.85(0.66-1.09)$ & $11.7(10.7-12.7)$ & 0.207 \\
\hline Obesity & $11.3(10.1-12.5)$ & 1 & $7.9(6.3-9.5)$ & $0.71(0.54-0.94)$ & $10.4(9.4-11.4)$ & 0.016 \\
\hline Prehypertension & $7.8(6.8-8.8)$ & 1 & $3.6(2.5-4.7)$ & $0.38(0.26-0.57)$ & $6.7(5.9-7.5)$ & $<0.001$ \\
\hline Hypertension & $9.7(8.6-10.8)$ & 1 & $2.9(1.9-3.9)$ & $0.27(0.18-0.40)$ & $7.8(7.0-8.6)$ & $<0.001$ \\
\hline Smoking & $9.2(8.1-10.3)$ & 1 & $14.6(12.5-16.7)$ & $1.41(1.10-1.80)$ & $10.7(9.7-11.7)$ & $<0.001$ \\
\hline Physical inactivity & $18.7(17.3-20.1)$ & 1 & $15.5(13.3-17.7)$ & $0.66(0.53-0.82)$ & $17.8(19.0-16.6)$ & $<0.001$ \\
\hline Inappropriate use of computer/TV & $32.6(30.9-34.3)$ & 1 & $36.1(33.2-39.0)$ & $1.47(1.23-1.77)$ & $33.4(31.9-34.9)$ & $<0.001$ \\
\hline Having no breakfast & $36.6(34.8-38.4)$ & 1 & $40.3(37.3-43.3)$ & $1.08(0.92-1.27)$ & $37.6(36.1-39.1)$ & 0.364 \\
\hline Inadequate fruit-vegetable consumption & $24.7(23.1-26.3)$ & 1 & $33.4(30.5-36.3)$ & $1.31(1.11-1.56)$ & $27.0(25.6-28.4)$ & 0.002 \\
\hline $\begin{array}{l}\text { Inadequate consumption of } \\
\text { sugar-sweetened beverages }\end{array}$ & $58.2(56.4-60.0)$ & 1 & $58.8(55.8-61.8)$ & $1.04(0.89-1.23)$ & $58.4(56.5-59.5)$ & 0.598 \\
\hline Physician-diagnosed diabetes mellitus & $0.4(0.3-0.5)$ & 1 & $1.4(0.7-2.1)$ & $2.28(0.96-5.40)$ & $0.7(0.6-0.8)$ & 0.060 \\
\hline $\begin{array}{l}\text { Family history of cardiovascular } \\
\text { disease }\end{array}$ & $44.5(42.7-46.3)$ & 1 & $43.8(40.8-46.8)$ & $1.05(0.89-1.23)$ & $44.3(42.7-45.9)$ & 0.555 \\
\hline
\end{tabular}

"OR values were adjusted for age, gender, family income level and dwelling sites.

urban areas, obesity was only associated with prehypertension, hypertension and family history of cardiovascular disease.

\section{DISCUSSION}

This study aimed to determine the risk factors associated with being overweight and obese in adolescents from rural vs. urban areas. In the study area, the selected socio-demographic characteristics are different in rural areas compared to urban areas. The lower rate of girls and higher mean age of students in rural areas result from the fact that girls in rural areas usually do not attend the school after the compulsory schooling of 8 years, and that children from rural areas usually attend the school in older ages (14). Adolescents from rural areas attend high schools in nearby urban areas. Because there are no high schools in particular rural areas, children have to continue their education in boarding schools. As shown in Turkish Statistical Institute 2013 data, the income level was found to be lower in rural than urban areas (14).

In this study, prevalence of obesity among high school students was found to be lower in rural areas compared to urban areas. The prevalence of obesity has increased steadily all over the world since the 1980s (3). Although obesity and being overweight is also prevalent in developed countries, the increase in the prevalence of obesity and being overweight is more noticeable in developing countries regardless of whether in rural or urban areas. The 
Table 3. Adjusted OR and 95\% Cl values for the risk factors accompanying obesity and overweight in adolescents according to rural/urban areas.

\begin{tabular}{|l|c|c|c|c|}
\hline \multirow{2}{*}{} & \multicolumn{2}{|c|}{ Urban } & \multicolumn{2}{c|}{ Rural } \\
\cline { 2 - 5 } & Overweight & Obese & Overweight & Obese \\
\hline Prehypertension & $\mathrm{OR}(95 \% \mathrm{Cl})^{*}$ & $\mathrm{OR}(95 \% \mathrm{Cl})^{*}$ & $\mathrm{OR}(95 \% \mathrm{Cl})^{*}$ & $\mathrm{OR}(95 \% \mathrm{Cl})^{*}$ \\
\hline Hypertension & $2.25(1.55-3.27)$ & $2.29(1.59-3.31)$ & $3.70(1.52-9.04)$ & $6.06(2.60-14.14)$ \\
\hline Smoking & $2.25(1.58-3.21)$ & $3.88(2.8-5.27)$ & $5.71(1.76-18.52)$ & $22.09(9.90-49.30)$ \\
\hline Physical inactivity & $0.90(0.58-1.38)$ & $1.05(0.70-1.59)$ & $1.37(0.77-2.44)$ & $0.94(0.47-1.88)$ \\
\hline Inappropriate use of computer/TV & $1.09(0.82-1.46)$ & $1.18(0.87-1.59)$ & $0.85(0.46-1.58)$ & $1.46(0.82-2.63)$ \\
\hline Having no breakfast & $0.97(0.75-1.24)$ & $1.32(1.03-1.68)$ & $0.82(0.50-1.34)$ & $1.15(0.65-2.02)$ \\
\hline Inadequate fruit-vegetable consumption & $1.16(0.91-1.47)$ & $1.33(1.04-1.69)$ & $0.87(0.56-1.34)$ & $1.21(0.75-1.93)$ \\
\hline Inadequate consumption of sugar-sweetened beverages & $1.01(0.77-1.31)$ & $1.03(0.79-1.36)$ & $0.93(0.60-1.45)$ & $0.85(0.52-1.40)$ \\
\hline Physician-diagnosed diabetes mellitus & $0.93(0.74-1.18)$ & $0.63(0.49-0.79)$ & $0.95(0.63-1.43)$ & $0.93(0.58-1.48)$ \\
\hline Family history of cardiovascular disease & $0.95(0.12-7.84)$ & $4.17(1.24-14.06)$ & $0.67(0.09-5.25)$ & $0.88(0.11-6.86)$ \\
\hline
\end{tabular}

* OR values were adjusted for age, gender, family income level and dwelling house.

previous studies from several countries have revealed that the prevalence of obesity in rural vs. urban areas varies between countries. The studies from America, Japan and Spain have reported higher prevalence of obesity in rural area, whereas those from China, Nigeria and India have found that prevalence of obesity was higher in urban areas (15-20). On the other hand, in Turkey, the prevalence of being overweight and obese in adolescents has been reported to be $9.9-17.6 \%$ and $1.6-7.8 \%$, respectively (21). In the study of Simsek et al., the prevalence of being overweight and obese in individuals living in urban areas is higher compared to rural areas by $4.9 \%$ and $3.8 \%$, respectively (22).

Obvious differences found in the comparison of risk factors between rural and urban areas are the reflection of living conditions in rural areas. A major problem emerging with the increasing prevalence of obesity among adolescents is the increasing prevalence of prehypertension in this age group (23). Because the blood pressure values may vary depending on the age, gender and body weight in adolescents, there is limited information about the regional distribution of the prevalence of hypertension and prehypertension. Often, the prevalence is underreported because of missed data.

In parallel to the obesity, prevalence of prehypertension and hypertension were also found to be higher in urban compared to rural areas. Several previous studies have found no difference in the prevalence of hypertension between rural and urban areas, whereas some have reported higher prevalence in rural areas and others in urban areas (24-26). As seen in our study, this might be due to the fact that prehypertension and hypertension are associated with obesity.

Regular physical activity during childhood and adolescence improves strength and endurance, helps the bones and muscles to be healthy, allows the body weight control, reduces anxiety and stress, increases self-esteem and stabilizes blood pressure and cholesterol levels (27). The living conditions caused by urbanization limit the activities of individuals, leading to a sedentary lifestyle. Previous studies have reported that the adolescents living in rural areas are usually more active than those from urban areas (28-31). Similar to the study of Ucar et al. carried out in the same region, we also found the number of actively living individuals to be higher in rural areas compared to urban areas (32). However, it is interesting in our results that time spent on computer/TV was higher in rural areas than urban areas. Because of the limited social activities and lack of hobbies for adolescents living in rural areas, the time spent on computer/TV might be increased (33). This may be regarded as the indication that sedentary lifestyle may also become prevalent in rural areas, leading to a physical inactivity level similar to the urban areas. In addition, there was no relationship between physical inactivity and overweightobesity in rural and urban areas. This result can be explained by the overweight-obese individuals' weight loss efforts, physical activity and individuals' dietary habits such as snacking.

The number of smokers among high school students is higher in rural areas than urban areas. Accordingly, in the "Turkey Burden of Disease Study", the prevalence of smoking among adults has been reported to be higher in rural areas than urban areas (34). Because of its place in the smoking epidemiology, Turkey is among the countries in which the smoking-induced morbidity and mortality will be high in the future. Despite the anti-smoking laws and media campaigns for children and adolescents in Turkey in recent years, the desired results have not yet been achieved in rural areas (35).

The higher prevalence of inadequate fruit and vegetable consumption in rural areas may be explained by the difficulty to access fresh vegetables and fruits (36). Because the main sources of income are animal husbandry and grain cultivation, fruit and vegetable cultivation is limited in rural Eskisehir. Therefore, fruits and vegetables have to be brought to rural areas from the city centre and because it is not always possible, nutrition-related problems may arise in these individuals living in rural areas.

Interestingly, in the logistic regression model, the factors associated with being overweight were similar for rural and urban areas, whereas the factors associated with obesity differed. In urban areas, obesity in adolescents was found to be associated with increased time spent on computer/TV, having no breakfast, physician-diagnosed diabetes mellitus, and consumption of sugarsweetened beverages.

The increased prevalence of being overweight and obese in younger population led to increased prevalence of essential 
hypertension (37). The risk of hypertension is 3 times higher in obese children compared to non-obese children $(38,39)$. In a study conducted in Europe by I'Allemand et al., $35.4 \%$ of children who were overweight were hypertensive (40).

Family history of cardiovascular disease is a major factor that should be emphasized in obese and overweight people. The role of genetic factors in the aetiology of obesity was demonstrated once again (1).

Having no breakfast is a major factor associated with obesity in urban areas. Although breakfast is a meal that is often overlooked, it is an important component of a healthy diet. Cross-sectional studies have demonstrated that regular breakfasting is associated with a lower risk of being overweight or obese among children and adolescents (41). Regularly breakfasting individuals are usually more active than those who do not and the fibre-rich foods in diet stabilize insulin and glucose levels in the body, thus maintaining a healthy body weight (41). The association found between obesity and consumption of sugar-sweetened beverages might result from the partial diet used by obese children.

Although the prevalence of excessive use of computer/TV was higher in rural areas, it should be emphasized that there was a significant association between the time spent on computer/TV and obesity in urban areas. Several previous studies have reported that obesity is positively associated with the increased time spent on computer/TV $(42,43)$. Watching TV and the use of media reduce the physical activity and metabolic rate. Moreover, eating high calorie foods (chips, nuts, etc.) during watching TV or using computer also leads to unhealthy life of children.

The prevalence of physician-diagnosed diabetes was assessed in the study. We underestimated the prevalence and there was no relationship found between physician-diagnosed diabetes and obesity in rural areas (44). One reason for this result may be that diabetic individuals are asymptomatic with type 1 diabetes. Therefore, the American Diabetes Association recommends regular screening for diabetes in children and adolescents. Despite the limitations of the study, our results also support this recommendation.

The major limitation of the study is the inability to analyze the cause and effect relationship due to the cross-sectional nature of the study. In addition, we could not find out the reflections of self-reported diet and physical activity assessments in rural and urban areas.

In conclusion, because the risk factors may differ between the adolescents from rural and urban areas, being overweight or obese should be followed up along with the risk factors. It is important in overweight and obese children to assess the family history of cardiovascular disease, blood pressure and blood glucose, to ask about the habit of regular breakfasting, and to evaluate time spent on computer/TV. As in urban areas, environmental regulations are becoming important in rural areas as well. Appropriate social activities for children to make them to spend more time in parks or playgrounds are important in urban as well as in rural areas.

\section{Acknowledgements}

The authors wish to thank students and doctors working on this study for their valuable efforts and time.

\section{Conflict of Interests}

None declared

\section{REFERENCES}

1. Lobstein T, Baur L, Uauy R; IASO International Obesity TaskForce. Obesity in children and young people: a crisis in public health. Obes Rev. 2004 May;5 Suppl 1:4-104.

2. Raj M. Obesity and cardiovascular risk in children and adolescents. Indian J Endocrinol Metab. 2012 Jan;16(1):13-9.

3. Herouvi D, Karanasios E, Karayianni C, Karavanaki K. Cardiovascular disease in childhood: the role of obesity. Eur J Pediatr. 2013 Jun;172(6):721-32.

4. de Onis M, Blössner M, Borghi E. Global prevalence and trends of overweight and obesity among preschool children. Am J Clin Nutr. 2010 Nov;92(5):1257-64.

5. Rising R, Harper IT, Fontvielle AM, Ferraro RT, Spraul M, Ravussin E. Determinants of total daily energy expenditure: variability in physical activity. Am J Clin Nutr. 1994 Apr;59(4):800-4.

6. Ghosh A. Rural-urban comparison in prevalence of overweight and obesity among children and adolescents of Asian Indian origin. Asia Pac J Public Health. 2011 Nov;23(6):928-35.

7. Befort CA, Nazir N, Perri MG. Prevalence of obesity among adults from rural and urban areas of the United States: findings from NHANES (20052008). J Rural Health. 2012 Fall;28(4):392-7.

8. Hanley AJ, Harris SB, Gittelsohn J, Wolever TM, Saksvig B, Zinman B. Overweight among children and adolescents in a Native Canadian community: prevalence and associated factors. Am J Clin Nutr. 2000 Mar;71(3):693-700.

9. Kann L, Kinchen SA, Williams BI, Ross JG, Lowry R, Grunbaum JA, et al.; State and Local YRBSS Coodinators. Youth Risk Behavior Surveillance System. Youth risk behavior surveillance - United States, 1999. MMWR CDC Surveill Summ. 2000 Jun 9;49(5):1-32.

10. WHO Multicentre Growth Reference Study Group. WHO Child Growth Standards based on length/height, weight and age. Acta Paediatr Suppl. 2006 Apr;450:76-85.

11. Asmar R, Khabouth J, Topouchian J, El Feghali R, Mattar J. Validation of three automatic devices for self-measurement of blood pressure according to the International Protocol: The Omron M3 Intellisense (HEM-7051-E), the Omron M2 Compact (HEM 7102-E), and the Omron R3-I Plus (HEM 6022-E). Blood Press Monit. 2010 Feb;15(1):49-54.

12. National High Blood Pressure Education Program Working Group on High Blood Pressure in Children and Adolescents. The fourth report on the diagnosis, evaluation, and treatment of high blood pressure in children and adolescents. Pediatrics. 2004 Aug;114(2 Suppl 4th Report):555-76.

13. World Health Organization. Chronic diseases and health promotion. STEPwise approach to surveillance (STEPS) [Internet]. Geneva: WHO [cited 2013 Feb 1]. Available from: http://www.who.int/chp/steps.

14. Turkish Statistical Institute (TUIK) [Internet]. Ankara [cited 2013 Jan 6 ]. Available from: www.tuik.gov.tr. (In Turkish.)

15. Musa DI, Toriola AL, Monyeki MA, Lawal B. Prevalence of childhood and adolescent overweight and obesity in Benue State, Nigeria. Trop Med Int Health. 2012 Nov; 17(11):1369-75.

16. Zhang YX, Wang SR. Prevalence and regional distribution of childhood overweight and obesity in Shandong Province, China. World J Pediatr. 2013 May;9(2):135-9.

17. Valdés Pizarro J, Royo-Bordonada MA. Prevalence of childhood obesity in Spain: National Health Survey 2006-2007. Nutr Hosp. 2012 JanFeb;27(1):154-60.

18. Davis AM, Bennett KJ, Befort C, Nollen N. Obesity and related health behaviors among urban and rural children in the United States: data from the National Health And Nutrition Examination Survey 2003-2004 and 2005-2006. J Pediatr Psychol. 2011 Jul;36(6):669-76.

19. Yadav K, Krishnan A. Changing patterns of diet, physical activity and obesity among urban, rural and slum populations in north India. Obes Rev. 2008 Sep;9(5):400-8.

20. Itoi A, Yamada Y, Watanabe Y, Kimura M. Physical activity, energy intake, and obesity prevalence among urban and rural schoolchildren aged 11-12 years in Japan. Appl Physiol Nutr Metab. 2012 Dec;37(6):1189-99.

21. Bereket A, Atay Z. Current status of childhood obesity and its associated morbidities in Turkey. J Clin Res Pediatr Endocrinol. 2012 Mar;4(1):1-7.

22. Simsek E, Akpinar S, Bahcebasi T, Senses DA, Kocabay K. The prevalence of overweight and obese children aged 6-17 years in the West Black Sea region of Turkey. Int J Clin Pract. 2008 Jul;62(7):1033-8.

23. Landsberg L, Aronne LJ, Beilin LJ, Burke V, Igel LI, Lloyd-Jones D, et al. Obesity-related hypertension: pathogenesis, cardiovascular risk, and treatment: a position paper of The Obesity Society and the American Society of Hypertension. J Clin Hypertens (Greenwich). 2013 Jan;15(1):14-33. 
24. Pavicević M, Pavicević D, Milosević B, Stojanović D. Arterial hypertension frequency in urban and rural population of children. Srp Arh Celok Lek. 2005 Mar-Apr;133(3-4):152-5. (In Serbian.)

25. Mohan B, Kumar N, Aslam N, Rangbulla A, Kumbkarni S, Sood NK, et al. Prevalence of sustained hypertension and obesity in urban and rural school going children in Ludhiana. Indian Heart J. 2004 Jul-Aug;56(4):310-4.

26. Sjöberg A, Moraeus L, Yngve A, Poortvliet E, Al-Ansari U, Lissner L. Overweight and obesity in a representative sample of schoolchildren - exploring the urban-rural gradient in Sweden. Obes Rev. 2011 May;12(5):305-14.

27. PAGAC. Physical Activity Guidelines Advisory Committee report, 2008 Washington, DC: U.S. Department of Health and Human Services; 2008.

28. Joens-Matre RR, Welk GJ, Calabro MA, Russell DW, Nicklay E, Hensley LD. Rural-urban differences in physical activity, physica fitness, and overweight prevalence of children. J Rural Health. 2008 Winter;24(1):49-54

29. Bathrellou E, Lazarou C, Panagiotakos DB, Sidossis LS. Physical activity patterns and sedentary behaviors of children from urban and rural areas of Cyprus. Cent Eur J Public Health. 2007 Jun;15(2):66-70.

30. Peer N, Bradshaw D, Laubscher R, Steyn N, Steyn K. Urban-rural and gender differences in tobacco and alcohol use, diet and physical activity among young black South Africans between 1998 and 2003. Glob Health Action. 2013 Jan 29;6:19216. doi: 10.3402/gha.v6i0.19216.

31. Vitáriušová E, Babinská K, Košt'álová L, Rosinský J, Hlavatá A, Pribilincová Z, et al. Food intake, leisure time activities and the prevalence of obesity in schoolchildren in Slovakia. Cent Eur J Public Health. 2010 Dec;18(4):192-7.

32. Uçar B, Kiliç Z, Colak O, Oner S, Kalyoncu C. Coronary risk factors in Turkish schoolchildren: randomized cross-sectional study. Pediatr Int. 2000 Jun;42(3):259-67.

33. Kosti RI, Panagiotakos DB. The epidemic of obesity in children and adolescents in the world. Cent Eur J Public Health. 2006 Dec;14(4):151-9.

34. Ünüvar N, Mollahaliloğlu S, Yardım N, editors. Turkey burden of disease study 2004. Ankara: Ministry of Health, Refik Saydam Hygiene Center Presidency, School of Public Health; 2006.
35. Ministry of Health of Turkey, General Directorate of Primary Health Care. Global Adult Tobacco Survey, Turkey Report. Ankara: Ministry of Health of Turkey; 2010.

36. Metintas S, Arikan I, Kalyoncu C. Awareness of hypertension and other cardiovascular risk factors in rural and urban areas in Turkey. Trans $\mathrm{R}$ Soc Trop Med Hyg. 2009 Aug; 103(8):812-8

37. Nur N, Cetinkaya S, Yilmaz A, Ayvaz A, Bulut MO, Sümer H. Prevalence of hypertension among high school students in a middle Anatolian province of Turkey. J Health Popul Nutr. 2008 Mar;26(1):88-94.

38. Sorof J, Daniels S. Obesity hypertension in children: a problem of epidemic proportions. Hypertension. 2002 Oct;40(4):441-7.

39. Rosner B, Prineas R, Daniels SR, Loggie J. Blood pressure differences between blacks and whites in relation to body size among US children and adolescents. Am J Epidemiol. 2000 May 15;151(10):1007-19.

40. I'Allemand D, Wiegand S, Reinehr T, Müller J, Wabitsch M, Widhalm K, et al.; APV-Study Group. Cardiovascular risk in 26,008 European overweight children as established by a multicenter database. Obesity (Silver Spring). 2008 Jul;16(7):1672-9.

41. Szajewska H, Ruszczynski M. Systematic review demonstrating that breakfast consumption influences body weight outcomes in children and adolescents in Europe. Crit Rev Food Sci Nutr. 2010 Feb;50(2):113-9.

42. Janssen I, Katzmarzyk PT, Boyce WF, Vereecken C, Mulvihill C, Roberts C, et al.; Health Behaviour in School-Aged Children Obesity Working Group. Comparison of overweight and obesity prevalence in school-aged youth from 34 countries and their relationships with physical activity and dietary patterns. Obes Rev. 2005 May;6(2):123-32.

43. Robinson TN. Television viewing and childhood obesity. Pediatr Clin North Am. 2001 Aug;48(4):1017-25.

44. Malecka-Tendera E, Erhardt E, Molnár D. Type 2 diabetes mellitus in European children and adolescents. Acta Paediatr. 2005 May;94(5):543-6.

Received September 16, 2013 Accepted in revised form January 7, 2015 